\title{
Serious games: supporting occupational engagement of people aged 50+ based on intelligent tutoring systems
}

\author{
Juegos serios: apoyo a la participación ocupacional de personas mayores \\ de 50 años basado en sistemas de tutoría inteligente
}

Mario A. Bruno ${ }^{1} \quad$ Laura Griffiths ${ }^{2}$

Recibido 14 de noviembre de 2012, aceptado 21 de octubre de 2013

Received: November 14, 2012 Accepted: October 21, 2013

\begin{abstract}
RESUMEN
Este artículo ofrece una visión general de los requisitos de juegos serios para apoyar la participación ocupacional de las personas mayores de 50 años de edad, y las características de dicho juego serio. Se realizó una revisión exhaustiva de la literatura y un cuestionario a 23 profesionales activos en el campo de la salud de la región de Valparaíso (Chile). Como resultado, entre los diversos requisitos establecidos, requisitos primarios fueron la evaluación de las habilidades de adaptación y de organización del espacio y de los objetos, así como de habilidades de intercambio de información y de coordinación, respecto de intervenciones basadas en ocupación y a rutinas dentro de un contexto social. A continuación se establecieron algunas características principales, como el uso de sistemas tutoriales inteligentes, adaptabilidad, balance de dificultad, estrategia en tiempo real, historias no lineales, y el razonamiento espacial, temporal y entre adversarios. En la discusión acerca de las características se especificaron en detalle el propósito, la estrategia y la personalización de un juego serio para personas mayores de 50 años.
\end{abstract}

Palabras clave: Juegos serios, tecnologías de información, atención de salud, participación ocupacional, personas mayores de 50 años.

\begin{abstract}
This paper offers an overview of the requirements of serious games to support occupational engagement for people at age 50 and above, and the features for such a serious game. A comprehensive literature revision and a questionnaire to 23 active in the field health professionals of the Valparaiso region (Chile) were performed. In the end, among the various requirements stated, primary requirements were the evaluation of adaptation skills and organizing space and objects skills as well as of information exchange skills and coordination skills, with respect to occupation-based interventions and routines within a social context. Afterwards, some primary features were stated, such as the use of intelligent tutoring systems, adaptability, difficulty balance, real-time strategy, non linear stories, and spatial, temporal and adversaries reasoning. In the discussion about the features, issues of purpose, strategy and the personalization of a serious game for people aged 50 and older were specified in detail.
\end{abstract}

Keywords: Serious games, information technologies, health, occupational engagement, older people.

\footnotetext{
1 Departamento de Computación e Informática. Facultad de Ingeniería. Advanced Research Center. Universidad de Playa Ancha. Traslaviña 450. Viña del Mar, Chile. E-mail: mbruno@upla.cl

2 Departamento de Computación e Informática. Facultad de Ingeniería. Universidad de Playa Ancha. Av. Leopoldo Carvallo 270. Valparaíso, Chile. E-mail: lgriffiths@upla.cl
} 


\section{INTRODUCTION}

Serious games, that engage users and contribute to achieving well-defined and more significant purposes than pure entertainment [1-2], have considerably increased their capabilities in recent years. A serious game is defined as "a mental contest, played with a computer in accordance with specific rules, that uses entertainment to further government or corporate training, education, health, public policy, and strategic communication objectives" [3]. Serious games as such were started to be applied in training, for example, in battle simulations for military training [2, 4]. Most of them have been developed from techniques and methods proposed in the last century [5-6]. Recently serious games are increasingly incorporating computational methods that can process information and profiles tailored to the interests of people 50 years and above, and potentially improve the use of existing technologies to support therapeutic intervention practices. In fact, as the elderly population is steadily growing, the labor force participation of the next generations will decrease for the labor supply, dramatically affecting the future development of national economies and productivity.

The promotion and protection of health is essential for human welfare and sustainable socio-economic development. In Chile, the old age dependency ratio (which is the ratio of the number of older dependents -people at an age when they are generally economically inactive -, i.e., aged 65 and over, compared to the number of people of working age, i.e., 15-64 years old) will increase between 2025 and 2050, from 33.3 to 51.1, respectively [7]. Most of the development and promotion programs are driven by public policies that are implemented through various agencies, both public and private services that depend on Ministry of Health, Municipalities, Compensation Funds and the autonomous community work groups. In 2010, the Valparaíso region had the greatest age dependency ratio in Chile, with 71 elderly for each 100 people under the age of 15 years old [8]. Furthermore, projections for year 2020 show that Valparaíso will be the most aged region where the number of elderly would be greater than that of the young population.

There has been an increasing recognition that occupation plays a central role in health and well-being. One of the main problems is the lack of technologies for interventions for occupation aimed at people 50+ that are perfectly functional. In general, technological instruments apply to people who have disabilities, and need health care facilities with a high cost associated, rather than the promotion of healthy lifestyles of people, to protect conditions for life outside work, and reduce the risk elements to reach the retirement age. Therapists attempt to implement instruments, at lower cost than health care, maintaining and developing the occupation with sufficient activity and autonomy in older people to reduce the likelihood of disease at an acceptable cost. Furthermore, therapeutic interventions lead to strengthening the capacity of older people to participate and share their own experience. Process and playing oriented activities are nutritious and enriching experiences, and engage them for many purposes. Among others, achieving and discharging more energy, gaining balance, moving from an existential state to another or getting only pleasure from it. Process-oriented activities such as games can lead to changes in lifestyle of people after age 50 [9]. Especially, when games increase awareness, it is possible to change or redesign people 50+ lifestyle. These activities include experiences in which risks are present in decision making processes, whether in the physical, mental or spiritual realm [10]. Nowadays, serious games have the potential to maintain the quality of life and productivity of older people.

This paper promotes this approach by contributing with an overview of the requirements and features of serious games for interventions for people 50+, relying on a comprehensive literature revision and a questionnaire to health professionals of the Valparaíso region.

\section{SERIOUS GAMES FOR PEOPLE 50+}

The emergence of the study of games as discipline goes back to Game Theory [11]. The performance of basic algorithms ("minimax") that model a game problem between opponents to decide a better play, can be improved by reducing the state space to be examined ("alpha-beta pruning").

A mathematical model that has extensively been used in games is Finite State Automata (FSA) that date back to the 1950s. Finite state automata 
FSA approaches ([12-13]) can describe the system behavior in terms of input and output events that occur to a game character, and change the current state of the game. That is, world events may force a change in the state. A FSA describes the output events produced depending on the state of the FSA (Moore model) or the inputs and state (Mealy model). FSA can be represented using different notations: state transition diagrams, state transition matrices, "if-then-else" scripts, etc. [14]

A technique that is typically used in the development of serious games is Pathfinding, which calculates the movements of a player character and nonplayer characters using heuristic search methods such as $A^{*}$ [15], which depends on the game domain information to find the least-cost path to a solution. Other steering techniques estimate the local movements of the solution neighborhood for route finding [16].

The making of programs that learn to play board games started with the application of reinforcement learning algorithms, which are based on the analogy of animal learning that shows how animals can learn arbitrary sequences of actions by only maximizing rewards: Q-Learning, Temporal Differences TD, etc. [17-19]. In recent years, techniques such as MonteCarlo Tree Search MCTS [20-21] have successfully been applied to computer games.

Under certain conditions these algorithms have been shown to adapt their behavior [22]. Adapting serious games refers to model behavior, difficulty levels and scenarios according to the player's abilities, so that the behavior is sufficiently challenging, the difficulty levels are balanced and the scenarios are of interest to the player. In general, adaptability in games [23] means that the visual and audio contents of the game are either customized by evaluating parameters and semantic information (e.g., to indicate to the game about the obstacles or difficulties that can be used with the decision-making of a player), or related to events produced by the interaction with the user. The latter consists in the ability to either provide automated game balancing (off-line mode) or to adjust to its players as they play (on-line mode), concurrently. Moreover, it is mandatory an architecture of techniques and methods for game adaptability to ensure adherence to serious games.
Users define their characteristics in order to adjust the interventions to their cognitive limitations, in order to evaluating their progress to enable them to advance in difficulty levels [24].

Here we present a classification of serious games on the basis of the distinction between (1) physiotherapy games, (2) cognitive-perceptual games, and (3) socio-emotional games.

\section{Physiotherapy Games}

Serious games have recently been implemented as therapeutic environments of virtual reality [25-26] for physical rehabilitation. The use of this kind of therapy has increased mainly due to the low cost of equipment such as Nintendo Wii [27]. Also, depending on the content of health care and the data obtained from user interaction, mobile games have been proposed for rehabilitation [28]. Physiotherapy games can provide learning experiences based on approaching the user with a closer representation to a digital simulation environment [29-30]. The design of 3D physiotherapy games has been facilitated considerably by the use of game engines [31], which in some cases can continuously adapt the game flow [32]. We can distinguish serious games that either run according to difficulty levels that user must overcome [33], or behave like open worlds [34].

"Exergaming", that combines exercise and video games to reduce sedentary lifestyles and improve health, have been developed, incorporating technologies that track the movement and physical activities [35-36]. Some are based on geolocation to increase physical activity, allowing people to play a game according to their position [37].

\section{Cognitive-Perceptual Games}

Serious games for cognitive stimulation and training have recently been researched and developed, in order to reduce the deterioration of executive functions [38-39]. Cognitive-perceptual games have been applied to either stimulate executive functions or recover after a stroke [40-41]. Thus, serious games can stimulate cognitive development and meet the needs of entertainment allowing the setting of a continuous interaction between the player's actions and responses from the computer, encouraging active participation and controlling the execution of the proposed activities for players. 
Cognitive-perceptual games can be supported by techniques of production systems and goal-oriented action planning. Rule-based or production systems are integrated in cognitive architectures, i.e., models that mimic human reasoning, such as SOAR [42]. With appropriate technology of optimized rules matching, some games may operate in real time with more than one million rules.

Real-Time Strategy, RTS, [43-46], which is typically found in games where players build armies to attack bases, is applied to problems of micro and macro management for planning and strategies generation [47-48]. RTS multiplayer games suffer from state explosion when handling requests for pathfinding of various players [49], especially in massively multiplayer online role-playing game, MMORPG [50].

Multiplayer games with ranking systems [51] incorporate statistical estimation methods to calculate the relative skill levels of players (for example, the ELO rating system). Additionally, other methods can identify and track the skills of players in a game mode to match them in batches of competition [52].

Cognitive-perceptual games that include spatial, temporal and adversaries reasoning [53] (e.g., video games where multiple players compete for resources and typically make decisions into $2 \mathrm{D}$ worlds [54]) use techniques of log data mining, evolutionary algorithms, reasoning under uncertainty and constraint programming. Techniques for spatial reasoning in serious games and their effects are discussed in [54-56].

Most cognitive training games that are currently marketed are designed for use to maintain or improve executive functions such as attentional control and memory.

\section{Socio-Emotional Games}

The production, design and usability of socioemotional games facilitate communication be-tween multiple users, including social interaction, communities and chat, and to keep in touch with close contacts [57-59].

Socio-emotional games such as RPG (Role-playing games) usually engage seniors in terms of emotional experiences. A subset of these games are First person shooter (FPS) and Third-person shooter games (TPS or 3PS) [60-61]. Several RPG games typically led to a real-time progress that combines interesting plots with different characters on appealed stories.

For RPG, non-player characters (NPC) are the adversaries and assistants in a game. The behavior of a NPC is the subject of considerable concern for using computational intelligence techniques in computer games. The identity of a NPC has become important in serious games such as MMORPG. Whether a character is either inherited by a player (well formed and attractive) or built from "scratch", the player will be "committed" to the game for learning a game (acting) and select, initially in terms of behavior, a character immersed in human social models. Decision trees [62-63], are structures that can describe the NPC behavior in a game or to determine who wins the game. Decision trees are typically implemented using if-then-else scripts. Furthermore, NPCs are usually driven by story and narrative in games.

In socio-emotional games based on narrative, the stories can be broken down into modules that communicate through events and resources associated with patterns [64]. Machine learning techniques, story grammars, planning and problem solving (Case-Based reasoning) have typically been used in this case [65-66].

Some approaches describe the behavior of characters and dialogue from system logs (logging) that keep trace of the user interaction [67-68]. It is noted that these methods require too many resources for development, adjustment and testing of general criteria and should be strongly modified and specialized for a specific game to obtain acceptable results. In Creatures [69], character behavior can be learned over time using neural networks and genetic algorithms. Resilient backpropagation, Rprop, is the learning method used for neural networks in games that offers the best performance [70].

One of the biggest challenges is dealing with socioemotional games based on non-linear stories [71-74]. For example, extracting stories over character arcs can be based on an abduction-based framework structured as constraint handling rules CHR with stored constraints expressed as temporal relations, etc. (while not goal oriented, [75] leads to discover 
narrative events via abduction by using weights on emotions related to the stories).

\section{Requirements}

With respect to the requirements for serious games for interventions of people 50+, where requirements are defined as something that is desired or needed, a study by [76] reveals that their motivations to play computer games were "to escape from reality, to stay in touch with society, and to give meaning to the day, and most have no need for multiplayer gaming". This study shows that a great difficulty with computer game play was "the overall and in-game speed, which mostly cannot be adjusted to age-related abilities". Likewise, a research by [77] shows that the key user requirements that interest older people are: challenge, socialization, fun, providing learning opportunities, and escape from daily routine. It is considered that serious games have higher barriers for learning than traditional computer applications when older people try to memorize story elements [78]. Moreover, improving the quality and quantity of digital content for people 50+ is very significant in an increasingly connected society to extend their self-worth, with focus on health promotion activities, environmental adjustment, self-care and training in the different aspects of the intervention process.

The intervention process facilitates engagement in occupation related to health and participation [79]. A well defined intervention plan can be supported by serious games. The intervention plan describes the types of interventions and is developed based on the results of the evaluation process to accomplish the purposes of a person 50+. The types of interventions include (a) Purposeful activity, (b) Consultation process, (c) Education process and (d) Occupationbased intervention activity. Purposeful activity consists in the use of occupations and activities of a person to train behaviors, within a therapeutic environment. In the Consultation process practitioners use their knowledge and experience to collaborate with a person, in organizations, institutions or groups. The Education process provides knowledge and information about occupation, health, and participation as training in a particular simulated occupation or activity. Finally, Occupation-based intervention activity consists in the therapeutic use of occupations and real activities of a person, who engages in client-directed occupations that meet the identified goals.
The practitioner can assess the enhanced ability of a person $50+$ to handle performance skills that enables commitment to the intervention goal. Performance skills, defined by Fisher [80] as observable, concrete, goal-oriented actions a person uses to engage in daily life occupations, can be effectively executed in activities using computer games. Among the multiple descriptions and categorization for performance skills, Fisher proposed the following: (a) motor skills, (b) communication/interaction skills, and (c) process skills. Motor skills consist in moving and interacting with task, objects, and environment, and include aspects of energy, strength and effort mobility, posture, and coordination. Communication/ interaction skills convey intentions and coordinate social behavior to act together with people, and include physicality, relations, and Information exchange. Process skills are used in managing and modifying actions while completing a task, and are comprised of energy, knowledge, temporal organization, organizing space and objects, and adaptation.

Recent studies [81] have shown that greater social participation in older people diminish their cognitive decline. Performance skills are influenced by several conditions of the environment within and surrounding the person. Context can be external to the client (physical, social, virtual); internal to the client (personal, spiritual); and may have external characteristics with beliefs and values that have been internalized (cultural context), and also may include a temporal dimension.

Context influences performance patterns that develop over time. While accomplishing occupations or activities, an individual adopts habits, routines, and roles. Habits such as dominating, useful and impoverished habits refer to specific, automatic behaviors. Routines are established sequences of occupations or activities that provide a structure. Roles are sets of behaviors assumed by society and may be defined by the client.

In summary, the literature revision shows that the revealed requirements correspond to the following aspects: (1) types of interventions, (2) performance skills, (3) motor skills, (4) communication/ interaction skills, (5) process skills, (6) context, and (7) performance patterns. We will follow these aspects in the rest of the paper. 


\section{Features}

To this end serious game must be equipped with a set of features, defined as distinctive aspects, qualities, or characteristics, helping and allowing persons aged 50 and older to develop appropriate activities.

The use of serious games that maintain the physical health of elderly has been categorized based on technology, user interaction and usability criteria [82]. Similarly, [83] suggests focus areas that serious games must achieve for rehabilitation: purpose, user interface, game dimension, single-player to multi-player, adaptable challenge, progress known by elderly and monitoring. For educational purposes (e-learning) and to improve human kinetics, treatment environments have great potential to support the management of the daily life of the people 50+ [84]. However, serious games that are relevant to rehabilitation are not adapted to the entertainment, and those that conform to gameplay are not suitable for rehabilitation [85].

For the maintenance of a certain level of cognitive skills for this domain [86], the most important features are spatial, temporal and adversaries reasoning, planning and strategies generation, ranking systems. RTS effects in older adults are analyzed in [87-88].

Automated tools based on models and languages for interactive narrative are considered very suitable for the people $50+$. To participate in socio-emotional games, people 50+ can relate their own memories to the contents of game story.

A very important feature is content customization of personalized serious games that depends on the user profile (for example, using clustering techniques). In this sense, serious games store and adopt user information, as well as provide difficulty levels based on the results of the players performance. Similarly, authoring and producing personalized digital content with its own capacity to adapt to different platforms, e.g., for mobile games promoting healthy lifestyles [89]. On the other hand, serious games with the support of semantic processing are used to demonstrate achievement of the intervention objectives [90].

\section{PRE-BACKLOG OF REQUIREMENTS}

The increasing interest in serious games is due to its potential to make learning more attractive and to maintain performance skills in o people $50+$. There is a need for a review of the requirements with regard to serious games for the intervention plans of people 50+. We are now at the first stage to establish a backlog of requirements from groups advocated to this domain of the Valparaíso region. We report a pre-backlog of requirements from health professionals of the Valparaíso region that will mostly be embracing serious games by means of a questionnaire.

\section{Method}

In the setting of the pre-backlog of requirements, we used a questionnaire. For the respondents, the selection sample included practitioners from the Valparaíso region having expertise in working with people 50+. These health professionals were specialists in kinesiology, psychology, occupational therapy and phonoaudiology. They work in public or private health institutions at the Valparaíso region. The general configuration, participants and procedure of the questionnaire are discussed in the following.

The respondents were invited to participate in a questionnaire through the contact points responsible of a therapy group working on this domain.

The questionnaire was administered to 23 practitioners of the Valparaíso region who work with people 50+. To accomplish this we contacted a list of professionals that met these requirements.

The questionnaire (see Table 1) consisted in 8 closed-ended questions, with multiple options to the participants that refer to the aspects of types of interventions, performance skills, motor skills, communication/interaction skills, process skills, context, performance patterns, and usage of computer games in interventions. We bring to mind that these aspects are relevant in conformance to the literature. Before applying the questionnaire, we validated it with occupational therapists. The questionnaire was made available in a web site. The analysis of the questionnaire allows us to establish whether the requirements do satisfy or not the situation of the Valparaíso region, where serious games are not commonly used in interventions.

\section{Questionnaire to practitioners}

In this part we discuss the results of the questionnaire to practitioners of the Valparaíso region that work with people $50+$. 
Table 1. Questionnaire on requirements of serious games for interventions for people over age 50 .

\begin{tabular}{|l|l|}
\hline Question & Description \\
\hline Q1 & $\begin{array}{l}\text { Which type of therapeutic interventions are you } \\
\text { most likely to use in care assistance for people } \\
\text { over age 50? }\end{array}$ \\
\hline Q3 & $\begin{array}{l}\text { From a professional standpoint, which of the } \\
\text { following performance skills can effectively be } \\
\text { executed in activities that incorporate computer } \\
\text { games? }\end{array}$ \\
\hline Q4 & $\begin{array}{l}\text { In your opinion, which motor skills in activities } \\
\text { using computer games for people over age 50 } \\
\text { are the most important and properly performed? }\end{array}$ \\
\hline Q5 & $\begin{array}{l}\text { In your opinion, which process skills in activities } \\
\text { using computer games for people over age 50 } \\
\text { are the most important and properly performed? }\end{array}$ \\
\hline Q6 & $\begin{array}{l}\text { In your opinion, which communication/interaction } \\
\text { skills in activities using computer games for } \\
\text { people over age 50 are the most important and } \\
\text { properly performed? }\end{array}$ \\
\hline Q7 & $\begin{array}{l}\text { In your opinion, which contexts using computer } \\
\text { games are better suited for the performance of } \\
\text { activities by people over age 50? }\end{array}$ \\
\hline Q8 & $\begin{array}{l}\text { In your opinion, which performance patterns } \\
\text { using computer games are better adopted by } \\
\text { people over age 50? }\end{array}$ \\
\hline $\begin{array}{l}\text { Do you use computer games in therapeutic } \\
\text { intervention plans for people over age 50? }\end{array}$ \\
\hline
\end{tabular}

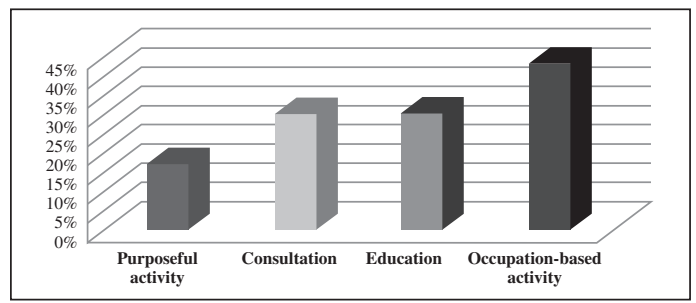

Figure 1. The most used types of interventions.

The questionnaire exposes that practitioners use different types of interventions and none of them is more important than the others. Nevertheless, according to Figure 1 about the percentages of responses that indicate the most used types of interventions in care assistance for people 50+, practitioners are likely to use and describe occupationbased intervention activity, followed by consultation and education processes in their intervention plans.

Among all the performance skills in activities using computer games, one common requirement emerged: process skills. We note that practitioners identify that process skills can better develop and maintain

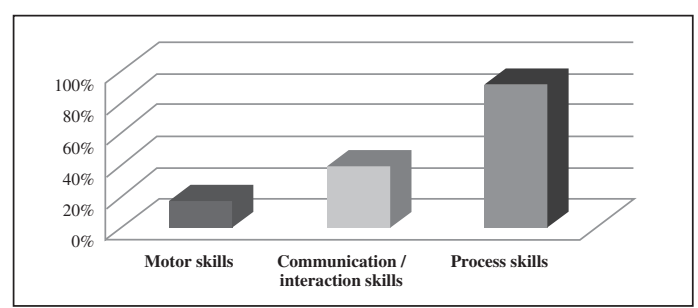

Figura 2. Skilled performance.

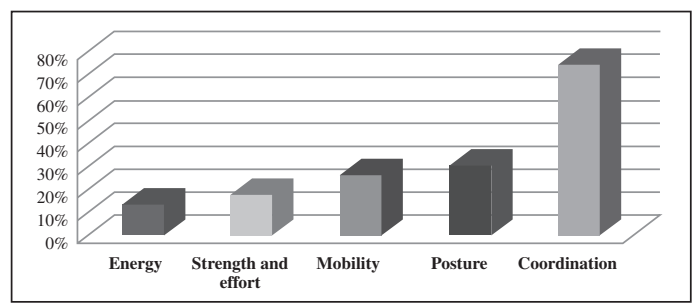

Figura 3. Importance and proper execution of process skills.

occupation for people 50+ during performance (see Figure 2). On the contrary, motor and communication/ interaction skills are less considered by practitioners. Among the process skills (see Figure 3), practitioners envision that there is a need to evaluate, above all, aspects such as preventing the adaptation (i.e., ability to anticipate, correct for and benefit by learning from the consequences of errors that arise in the course of task performance), and organizing space and objects (i.e., skills for organizing task workspaces and objects). Although evaluating motor and communication/interaction skills is less considered by practitioners, here we observe that practitioners make the point of the importance of evaluating the coordination aspect, i.e., using more than one body part to interact with task objects in a manner that supports task performance (see Figure 4), as well as the information exchange aspect (see Figure 5).

Figure 6 describes the percentages of responses that designate the positively influence of con-texts, in which activities using computer games occur. We note that the social context is indicated as best suited to perform activities for people 50+.

According to the percentages of respondents that indicate the better performance patterns adopted in activities in Figure 7, using computer games by people $50+$, we observe and the trend is that routines are suitably adopted in intervention plans. 


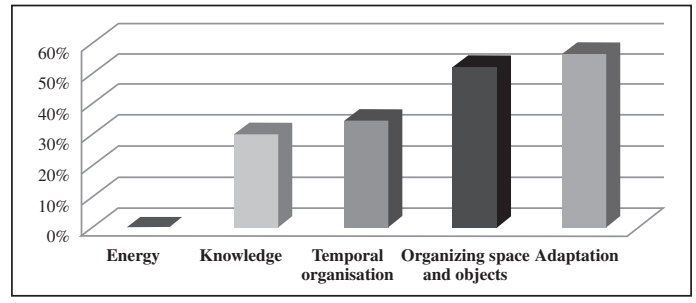

Figura 4. Importance and proper execution of motor skills.

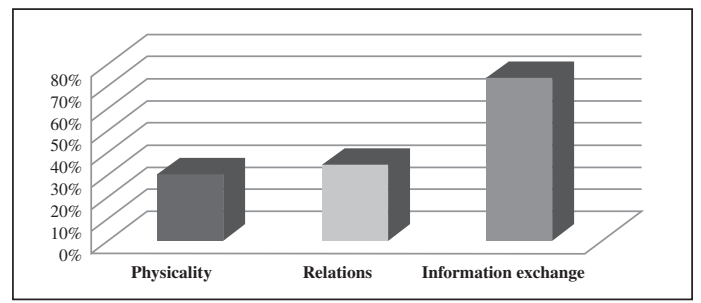

Figura 5. Importance and proper execution of communication/interaction skills.

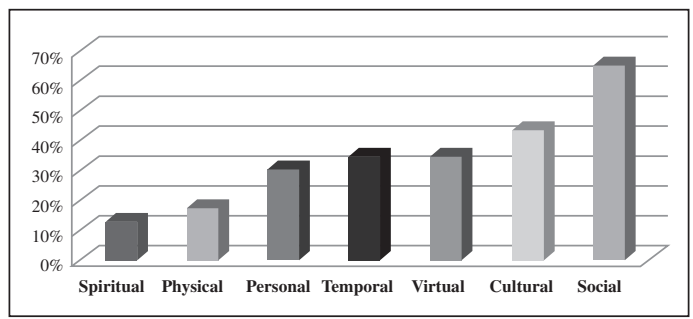

Figura 6. Positive influence of contexts.

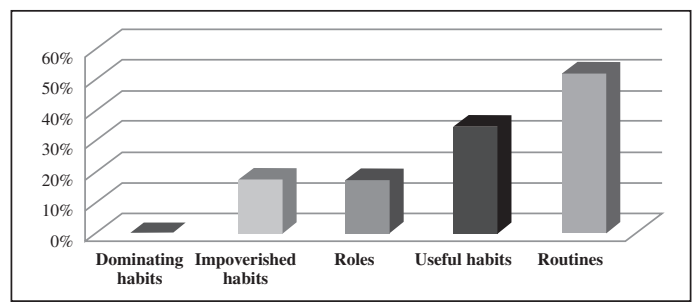

Figura 7. Adoption of performance patterns.

In Figure 8 the percentages of respondents are shown that indicate the use of computer games in the intervention process.

\section{SPECIFYING THE FEATURES}

From the results obtained of the combination of evidence of practitioners and the literature revision, we specify the main features for serious games

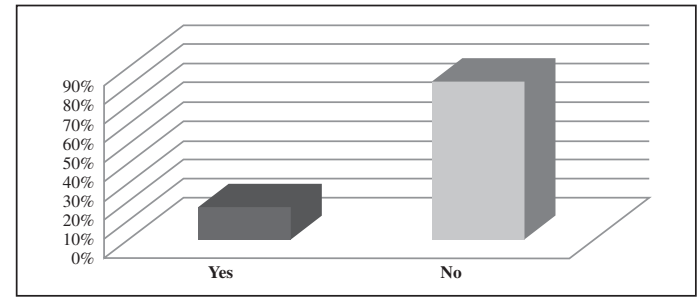

Figura 8. Usage of computer games.

supporting interventions plans for people $50+$. We start with a brief discussion about the results of the questionnaire, and then we discuss the way to engineering the questionnaire results to features for serious games aimed at the application area.

\section{Global discussion}

When comparing the questionnaire results, we note some appealing contrasts in the results. In other words, for intervention plans that include computer games for people $50+$, practitioners give importance to evaluating process skills on a social context, but on the other hand aspects of communication/ interaction skills are not considered relevant. A reason of this fact may be that practitioners are aware of the increasing availability of computer games for cognitive training (a marketing trend which is not our research concern) or may do not know another kind of computer games.

Additionally, we observe that a context generated by the presence of persons, groups, and organizations that surround the person after age 50 do receive more attention by practitioners than the performance on physical or virtual contexts. On this matter, the construction of a virtual 3D environment or the way that the game is played may not be a demand for a serious game, but the production of the circumstances in which the social context can influence some activity in the intervention process, as well as the routines, by practitioners in collaboration with the client. According to this perception we deduce that enabling the creation of these conditions may permit to exploit the effective application of serious games in their intervention. We will proceed to describe the mapping of the questionnaire results discussed to features in the following.

Transforming questionnaire results to features In this part we discuss the way to map the questionnaire results to features for serious games 
for people $50+$ in intervention processes. Here we focus on (A) purpose of the serious game, (B) its strategy, and (C) its personalization.

A) Purpose: In conformity with [78], the questionnaire applied to practitioners expresses that their requirements primarily pertain to assess process skills of elderly within a social context. In this regard, the questionnaire also expresses that their requirements pertain to indicators on process skills of adaptation (that is, anticipating errors, profiting by learning) and organizing task objects and spaces (that is, gathering tools and materials, searching). On the other hand, since the social context is fully related to information exchange skills (that is, giving and receiving information within an occupation), we may consider that as a feature for the domain of people $50+$, the purpose of a serious game should be to manage and assess both process skills as well as communication/ interaction skills.

B) Strategy: With respect to the strategy, we observe that a serious game with a purpose of assessing process skills and communication/interaction skills within a social context should take into account cognitive and real-time strategies, as well as spatial, temporal and adversaries reasoning. According to literature, as long as routines for the maintenance of cognitive abilities are important, we may consider a serious game with as strategy a micro management of planning generation, i.e., a mission for a singleplayer game or a non linear story that enables the socialization. To enhance the performance of such skills for consultation and education processes, a serious game may be an effective educational method that provides a safe environment for trial and error, and immediate feedback to the user.

C) Personalization: According to literature, serious games must be adapted to the user profile, in activities that are consistent with the difficulty levels to achieve the best results. A possible implementation may be the use of adaptability [91], pervasive narrative [92], and difficulty balance [93], for controlling the execution of the proposed skills and encouraging the active participation of the client. With regard to profile definition, we may consider serious games with adjustment of parameters obtained by computer vision and a voice recognition system connected to sensor networks, where parameters may be the objects and sounds associated with the social context. A possible implementation may be intelligent tutoring systems based on personalized web with rich social interactions, using deductive logic or narrative models, which have proved to be effective in achieving learning outcomes [94].

\section{CONCLUSIONS}

In this paper we made inquires about serious games for interventions for people over age 50. In particular, we made inquires about the requirements of serious games for this selected domain and the features for these serious games. In our approach, we realized a comprehensive review of literature, and realized a questionnaire to 23 health professionals of the Valparaíso region concerned with therapeutic interventions. We stated some requirements, primarily the maintenance within a social context of process skills as well as communication/interaction skills, with respect to routines and occupationbased interventions. Afterwards we stated several features that concern primarily the application of computational methods for intelligent tutoring systems, difficulty balance, real-time strategy, non linear stories, spatial, temporal and adversaries reasoning. When analyzing the features, we specified the criteria of purpose, strategy and personalization of a serious game for this particular domain.

For future work, additional studies may expand the geographic coverage in data collection because most of the health professionals that work on this particular domain are mainly located on the Area Metropolitana region. Considering the relative growth of the aging population, this work addresses a topic of high social and economic impact.

\section{ACKNOWLEDGMENTS}

The research was supported by the Advanced Research Center of the Universidad de Playa Ancha. The authors wish to thank Luzmarina Silva and Dalila Goudeau of Occupational Therapy from the Universidad de Playa Ancha for their help.

\section{REFERENCES}

[1] D.R. Michael and S.L. Chen. "Serious Games: Games That Educate, Train, and Inform". Boston, MA. Thomson Course Technology. 
1st Edition. Vol. 1, pp. 21-24. Boston, USA. 2006. ISBN: 1-59200-622-1.

[2] C.C. Abt. "Serious Games". Lanham, MD: University Press of America. 1st Edition. Vol. 1, pp. 10-14. New York, NY, USA. 1987. ISBN: $0819161489,9780819161482$. (Reprint. Originally published: New York: Viking Press, 1970.)

[3] M. Zyda. "From visual simulation to virtual reality to games". Computer. Vol. 38, Issue 9, pp. 25-32. September, 2005. ISSN: 00189162. DOI: 10.1109/MC.2005.297.

[4] M. Zyda, J. Hiles, A. Mayberry, C. Wardynski, M. Capps, B. Osborn, R. Shilling, M. Robaszewski and M. Davis. "Entertainment R\&D for defense". IEEE Comput. Graph. Appl. Vol. 23, Issue 1, pp. 28-36. January, 2003. ISSN: 0272-1716. DOI: 10.1109/ MCG.2003.1159611.

[5] C.E. Shannon. "Programming a computer for playing chess". Philosophical Magazine. Vol. 41, Issue 314, pp. 256-275. March, 1950. ISSN: 1478-6435 (Print), 1478-6443 (Online). DOI: 10.1080/14786445008521796.

[6] R.S. Sutton and A.G. Barto. "Reinforcement learning: an introduction". A Bradford Book. The MIT Press. 1st Edition. Vol. 1, pp. 14-20. Cambridge, MA, USA. 1998. ISBN: 0262193981.

[7] UN. "World population prospects: The 2010 revision”. 2010. Date of visit: July 28, 2011. URL: http://esa.un.org/unpd/wpp/index.htm

[8] Instituto Nacional de Estadísticas (INE). "Enfoque estadístico. Población adulta mayor en el bicentenario". 2010.

[9] G. Kielhofner. "Conceptual foundations of occupational therapy practice". G- Reference, Information and Interdisciplinary Subjects Series. F.A. 4th Edition. Vol. 1, pp. 31. Davis Co. Philadelphia, USA. 2009. ISBN-10: 0803620705 ISBN-13: 978-0803620704.

[10] F. Vanclay. "International principles for social impact assessment". Impact assessment and project appraisal. Vol. 21, Issue 1, pp. 5-11. March, 2003. ISSN: 14615517. DOI: 10.3152/147154603781766491.

[11] J. Von Neumann and O. Morgenstern. "Theory of games and economic behavior". Princeton University Press. $3^{\text {rd }}$ Edition. Vol. 1, pp. 48-60. Princeton, USA. 1953. ISBN-10: 0471911852. ISBN-13: 9780471911852.
[12] G.H. Mealy. "A method for synthesizing sequential circuits". Bell System Technical Journal. Vol. 34, Issue 5, pp. 1045-1079. September, 1955. DOI: 10.1002/j.15387305.1955.tb03788.x.

[13] E.F. Moore. "Gedanken-experiments on sequential machines". Automata Studies, Annals of Mathematical Studies, Princeton University Press. No 34, pp. 129-153. Preston NJ, USA. 1956.

[14] M.J. Taylor, D. Gresty and M. Baskett. "Computer game-flow design". Computers in Entertainment (CIE). Vol. 4, Issue 5, pp. 1-10. January, 2006. ISSN: 1544-3574. DOI: $10.1145 / 1111293.1111300$.

[15] T.C. Hou John, E.C. Prakash and N.S. Chaudhari. "Team AI: probabilistic pathfinding". International conference on Game research and development (CyberGames '06), Murdoch University. Western Australia, Australia. December 4-6, 2006.

[16] A. Nareyek. "AI in computer games". Queue. Vol. 1, Issue 10, pp. 58-65. February, 2004. DOI: 10.1145/971564.971593.

[17] L.P. Kaelbling, M.L. Littman and A.W. Moore. "Reinforcement learning: a survey". J. Artif. Int. Res. Vol. 4, Issue 1, pp. 237-285. May, 1996. ISSN: 11076-9757. DOI: 10.1613/ jair.301.

[18] C. Szepesvári. "Algorithms for Reinforcement Learning". Synthesis Lectures on Artificial Intelligence and Machine Learning. Morgan \& Claypool Publishers. 1st Edition. Vol. 1, pp. 18-36, 56-59. ISBN: 9781608454921 (Print). ISBN: 9781608454938 (Online). 2010.

[19] D. Silver, R.S. Sutton, and M. Muller. "Temporal-difference search in computer go". Mach. Learn. Vol. 87, Issue 2, pp. 183219. May, 2012. ISSN: 0885-6125. DOI: 10.1007/s10994-012-5280-0.

[20] C. Browne and F. Maire. "Evolutionary game design". IEEE Transactions on Computational Intelligence and AI in Games. Vol. 2, Issue 1, pp. 1-16. March, 2010. ISSN: 1943-068X. DOI: 10.1109/TCIAIG.2010.2041928.

[21] S. Gelly, L. Kocsis, M. Schoenauer, M. Sebag, D. Silver, C. Szepesvári and O. Teytaud. "The grand challenge of computer go: Monte carlo tree search and extensions". 
Commun. ACM. Vol. 55, Issue 3, pp. 106113. March, 2012. ISSN: 00010782. DOI: $10.1145 / 2093548.2093574$.

[22] A. Farahmand and C. Szepesvári. "Model selection in reinforcement learning". Mach. Learn. Vol. 85, Issue 3, pp. 299-332. December, 2011. ISSN: 0885-6125 (Print) ISSN: 1573-0565 (Online). DOI: 10.1007/ s10994-011-5254-7.

[23] R. Lopes and R. Bidarra. "Adaptivity challenges in games and simulations: A survey". IEEE Transactions on Computational Intelligence and AI in Games. Vol. 3, Issue 2, pp. 85-99. June, 2011. ISSN: 1943-068X. DOI: 10.1109/TCIAIG.2011.2152841.

[24] E. Prakash, G. Brindle, K. Jones, S. Zhou, N.S. Chaudhari and K. Wong. "Advances in games technology: Software, models, and intelligence". Simul. Gaming. Vol. 40, Issue 6, pp. 752-801. December, 2009. ISSN: 1046-8781 (Print) 1552-826X (Online). DOI: 10.1177/1046878109335120.

[25] C. Anderson-Hanley, A.L. Snyder, J.P. Nimon and P.J. Arciero. "Social facilitation in virtual reality-enhanced exercise: competitiveness moderates exercise effort of older adults". Clin. Interv. Aging. Vol. 6, pp. 275-280. October, 2011. ISSN: 1178-1998 (Online). DOI: 2011. 10.2147/CIA.S25337.

[26] A. Conconi, T. Ganchev, O. Kocsis, G. Papadopoulos, F. Fernández-Aranda and S. Jiménez-Murcia. "Playmancer: A serious gaming 3d environment". International Conference on Automated solutions for Cross Media Content and Multi-channel Distribution (AXMEDIS '08). Florence, Italy. November 17-19, 2008.

[27] Y. Theng, A. Bin Dahlan, M.L. Akmal and T. Zin Myint. "An exploratory study on senior citizens' perceptions of the nintendo wii: the case of singapore". 3rd International Convention on Rehabilitation Engineering \& Assistive Technology (i-CREATe '09). Singapore. April 22-26, 2009.

[28] J. Sunwoo, W. Yuen, C. Lutteroth and B. Wunsche. "Mobile games for elderly healthcare". 11th International Conference of the NZ Chapter of the ACM Special Interest Group on Human-Computer Interaction (CHINZ '10). Auckland, New Zealand. July 8-9, 2010.
[29] M.N.K. Boulos, L. Hetherington and S. Wheeler. "Second Life: an overview of the potential of 3-D virtual worlds in medical and health education". Health Information \& Libraries Journal. Vol. 24, Issue 4, pp. 233-245. December, 2007. ISSN: 1471-1842 (Online). DOI: 10.1111/j.1471-1842.2007.00733.x.

[30] E. Klopfer, J. Perry, K. Squire and M. Jan. "Collaborative learning through augmented reality role playing". Conference on Computer support for collaborative learning: learning 2005: the next 10 years! (CSCL '05). Taipei, Taiwan. May 30-June 4, 2005.

[31] P. Petridis, I. Dunwell, S. de Freitas and D. Panzoli. "An engine selection methodology for high fidelity serious games". Second International Conference on Games and Virtual Worlds for Serious Applications (VS-GAMES '10). Braga, Portugal. March 25-26, 2010.

[32] F. Bellotti, R. Berta, A. De Gloria and L. Primavera. "Adaptive experience engine for serious games". IEEE Transactions on Computational Intelligence and AI in Games. Vol. 1, Issue 4, pp. 264-280. December, 2009. ISSN: 1943-068X. DOI: 10.1109/ TCIAIG.2009.2035923

[33] J. Hagelbáck and S.J. Johansson. "Measuring player experience on runtime dynamic difficulty scaling in an rts game". CIG'09 5th international conference on Computational Intelligence and Games. Milan, Italy. September 7-10, 2009.

[34] L. Jarmon, T. Traphagan, M. Mayrath and A. Trivedi. "Virtual world teaching, experiential learning, and assessment: An interdisciplinary communication course in second life". Comput. Educ. Vol. 53, Issue 1, pp. 169-182. August, 2009. ISSN: 0360-1315. DOI: 10.1016/j.compedu.2009.01.010.

[35] L.R. Boschman. "Exergames for adult users: a preliminary pilot study". International Academic Conference on the Future of Game Design and Technology (Futureplay '10). Vancouver, BC, Canada. May 6-7, 2010.

[36] T. Morelli, J. Foley and E. Folmer. "Vibowling: a tactile spatial exergame for individuals with visual impairments". 12th international ACM SIGACCESS conference on Computers and accessibility (ASSETS ' 10 ). Orlando, Florida, USA. October 25-27, 2010. 
[37] D. Estrin, K. Mani Chandy, R. Michael Young, L. Smarr, A. Odlyzko, D. Clark, V. Reding, T. Ishida, S. Sharma, V.G. Cerf, U. Holzle, L.A. Barroso, G. Mulligan, A. Hooke and C. Elliott. "Internet predictions". IEEE Internet Computing. Vol. 14, Issue 1, pp. 12-42. January, 2010. ISSN: 1089-7801. DOI: 10.1109/MIC.2010.12.

[38] P.A. Roman and D. Brown. "Games-Just how serious are they?". The Interservice/ Industry Training, Simulation \& Education Conference (I/ITSEC). Vol. 2008, Issue 1. National Training Systems Association. Orlando, FL, USA. December 14, 2008.

[39] L. Gamberini, M. Alcaniz, G. Barresi, M. Fabregat, B. Seraglia and L. Prontu. "Playing for a real bonus: Videogames to empower elderly people". Journal of CyberTherapy \& Rehabilitation. Vol. 1, Issue 1, pp. 37-48. Spring 2008. ISSN 1784-9934.

[40] T. Petsatodis, A. Pnevmatikakis, F. Talantzis and U. Diaz. "Interactive surfaces for enhanced cognitive care". 16th Int Digital Signal Processing Conf. Santorini, Greece. July 5-7, 2009.

[41] G.E. Smith, P. Housen, K. Yaffe, R. Ruff, R.F. Kennison, H.W. Mahncke and E.M. Zelinski. "A cognitive training program based on principles of brain plasticity: Results from the improvement in memory with plasticity-based adaptive cognitive training (IMPACT) study". Journal of the American Geriatrics Society. Vol. 57, Issue 4, pp. 594-603. April, 2009. ISSN: 0002-8614 (Print) 1532-5415 (Online). DOI: $10.1111 /$ j.1532-5415.2008.02167.x.

[42] J.E. Laird, A. Newell and P.S. Rosenbloom. "Soar: an architecture for general intelligence". Artif. Intell. Vol. 33, Issue 1, pp. 1-64. September, 1987. ISSN: 0004-3702. DOI: 10.1016/0004-3702(87)90050-6

[43] M. Bardini, F. Bellotti, R. Berta and A. De Gloria. "Enabling dynamic generation of levels for RTS serious games". Entertainment Computing. Vol. 2, Issue 2, pp. 123-131. 2010. ISSN 1875-9521. DOI: 10.1016/j. entcom.2010.12.005.

[44] J. Togelius, M. Preuss, N. Beume, S. Wessing, J. Hagelback and G.N. Yannakakis. "Multiobjective exploration of the starcraft map space". IEEE Symp. Computational
Intelligence and Games (CIG). Copenhagen, Denmark. August 18-21, 2010.

[45] D. Christensen, H.O. Hansen, J.P. Cordero Hernandez, L. Juul-Jensen, K. Kastaniegaard and Y. Zeng. "A data-driven approach for resource gathering in real-time strategy games". 7th international conference on Agents and Data Mining Interaction (ADMI'11). Taipei, Taiwan. May 2-6, 2011.

[46] M. Chung, M. Buro and J. Schaeffer. "Monte carlo planning in RTS games". IEEE Symposium on Computational Intelligence and Games (CIG05). Colchester, Essex, UK. April 4-6, 2005.

[47] J. McCoy and M. Mateas. "An integrated agent for playing real-time strategy games". 23rd national conference on Artificial intelligence (AAAI'08). Vol. 3. Chicago, USA. July 13-17, 2008.

[48] R. Metoyer, S. Stumpf, C. Neumann, J. Dodge, J. Cao and A. Schnabel. "Explaining how to play real-time strategy games". Know.-Based Syst. Vol. 23, Issue 4, pp. 295-301. May, 2010. ISSN: 0950-7051. DOI: 10.1016/j. knosys.2009.11.006.

[49] M.T. Tsapanos, K.C. Chatzidimitriou and P.A. Mitkas. "A zeroth-level classifier system for real time strategy games". IEEE/WIC/ ACM International Conferences on Web Intelligence and Intelligent Agent Technology. (WI-IAT ' 11). Vol. 2. Lyon, France. August 22-27, 2011.

[50] T. Fritsch, H. Ritter and J. Schiller. "The effect of latency and network limitations on mmorpgs: a field study of everquest2". 4th ACM SIGCOMM workshop on Network and system support for games (NetGames '05). Hawthorne, NY, USA. October 10-11, 2005.

[51] R. Coulom. "Computing ELO ratings of move patterns in the game of go". Computer Games Workshop. Amsterdam, Netherlands. June 15-17, 2007.

[52] S. Hacker and L. von Ahn. "Matchin: eliciting user preferences with an online game". 27th international conference on Human factors in computing systems (CHI '09). Boston, USA. April 4-9, 2009.

[53] A.G. Cohn and S.M. Hazarika. "Qualitative spatial representation and reasoning: An overview". Fundam. Inf. Vol. 46, Issue 1-2, pp. 1-29. January, 2001. ISSN:0169-2968. 
[54] K. Rapantzikos, Y. Avrithis and S. Kollias. "Spatiotemporal features for action recognition and salient event detection". Cognitive Computation, special issue on Saliency, attention, visual search and picture scanning. Vol. 3, Issue 1, pp. 167-184. March, 2011. ISSN: 1866-9956 (Print) 1866-9964 (Online). DOI: 10.1007/s12559-011-9097-0.

[55] A. Corradini. "Tailoring the interpretation of spatial utterances for playing a board game". 13th international conference on Artificial Intelligence: Methodology, Systems, and Applications (AIMSA '08). Varna, Bulgaria. September 4-6, 2008.

[56] A. Corradini. "A study on whether digital games can effect spatial reasoning skills". In Handbook of Research on Improving Learning and Motivation through Educational Games: Mul-tidisciplinary Approaches. IGI Global. 1st Edition. Vol. 1, pp. 1086-1110. ISBN-10: 1609604954 ISBN-13: 9781609604967. 2011.

[57] Z. Zhou, A.D. Cheok, S.P. Lee, L.N. Thang, C.K. Kok, W.Z. Ng, Y.K. Cher, M.L. Pung and Y. Li. "Age invader: human media for natural social-physical inter-generational interaction with elderly and young". Int. Conf. Active Media Technology (AMT 2005). Kagawa, Japan. May 19-21, 2005.

[58] N. Shim, R. Baecker, J. Birnholtz, and K. Moffatt. "Tabletalk poker: an online social gaming environment for seniors". International Academic Conference on the Future of Game Design and Technology (Futureplay '10). Vancouver, Canada. May 6-7, 2010.

[59] P. Keyani, G. Hsieh, B. Mutlu, M. Easterday and J. Forlizzi. "Dancealong: supporting positive social exchange and exercise for the elderly through dance". Human factors in computing systems (CHI '05). Portland, OR, USA. April 2-7, 2005.

[60] J.E. Laird. "Using a computer game to develop advanced AI". Computer. Vol. 34, Issue 7, pp. 70-75. July, 2001. ISSN: 00189162. DOI: $10.1109 / 2.933506$.

[61] N. Cole, S.J. Louis and C. Miles. "Using a genetic algorithm to tune first-person shooter bots". IEEE Congress on Evolutionary Computation (CEC2004). Portland, OR, USA. June 19-23, 2004.
[62] J.R. Quinlan. "Learning efficient classification procedures and their application to chess end games". In Machine Learning: An Artificial Intelligence Approach. Tioga Pub. Co. 1st Edition. Vol. 1, pp. 463-482. Palo Alto, CA, USA. ISBN: 0935382054, 9780935382051. 1983.

[63] J.R. Quinlan. "Induction of decision trees". Mach. Learn. Vol. 1, Issue 1, pp. 81-106. March, 1986. ISSN 0885-6125 (Print) 15730565 (Online). DOI: 10.1007/BF00116251.

[64] F. Song and R. Cohen. "The interpretation of temporal relations in narrative". 7th National (US) Conference on Artificial Intelligence. St. Paul, MN. USA. August 21-26, 1988.

[65] M.O. Riedl, C.J. Saretto and R. Michael Young. "Managing interaction between users and agents in a multi-agent storytelling environment". Second international joint conference on Autonomous agents and multiagent systems (AAMAS '03). Melbourne, Australia. July 14-18, 2003.

[66] P. Gervs, B. Lnneker-Rodman, J.C. Meister and F. Peinado. "Narrative models: Narratology meets artificial intelligence". International Conference on Language Resources and Evaluation. Satellite Workshop: Toward Computational Models of Literary Analysis. Genova, Italy. May 22, 2006.

[67] Y. Cheong, A. Jhala, B. Bae and R. Michael Young. "Automatically generating summary visualizations from game logs". Fourth Artificial Intelligence and Interactive Digital Entertainment Conference (AIIDE). Stanford, CA, USA. October 22-24, 2008.

[68] L. Chittaro and R. Ranon. "Serious games for training occupants of a building in personal fire safety skills". Conference in Games and Virtual Worlds for Serious Applications (VS-GAMES '09). Coventry, UK. March 23-24, 2009.

[69] D. Cliff and S. Grand. "The creatures global digital ecosystem”. Artificial Life. Vol. 5, Issue 1, pp. 77-94. Winter 1999. ISSN: 10645462. DOI: 10.1162/106454699568683.

[70] L. Kocsis, C. Szepesvári and M.H.M. Winands. "RSPSA: enhanced parameter optimization in games". 11th international conference on Advances in Computer Games (ACG'05). Taipei, Taiwan. September 6-8, 2005. 
[71] R. Michael Young. "Extending models of conflict and intent dynamics in narrativebased virtual worlds". ACM SIGMM conference on Multimedia systems (MMSys '10). Scottsdale, AZ, USA. February 22-23, 2010.

[72] M. Cavazza, F. Charles and S.J. Mead. "Character-based interactive storytelling". IEEE Intelligent Systems. Vol. 17, Issue 4, pp. 17-24. July/August 2002. ISSN: 15411672. DOI: 10.1109/MIS.2002.1024747.

[73] R. Champagnat, G. Delmas and M. Augeraud. "A storytelling model for educational games: hero's interactive journey". Int. J. Technol. Enhanc. Learn. Vol. 2, Issue 1/2, pp. 4-20. January, 2010. ISSN: 1753-5255 (Print) 1753-5263 (Online). DOI: 10.1504/ IJTEL.2010.031257.

[74] M.O. Riedl. "Interactive narrative: A novel application of artificial intelligence for computer games (invited paper)". 26th AAAI Conference on Artificial Intelligence. Ontario, Canada. July 22-26, 2012.

[75] R. Perez y Perez and A. Atocha. "The role of abduction in automatic storytelling". AAAI workshop in Computational Aesthetics: AI Approaches to Beauty \& Happiness (AAAI06). Boston, MA, USA. July 16-17, 2006.

[76] H.H. Nap, Y.A.W. de Kort and W.A. IJsselsteijn. "Senior gamers: preferences, motivations and needs". Gerontechnology. Vol. 8, Issue 4, pp. 247-262. Autumn 2009. ISSN 1569-1101 (Print) 1569-111X (Online). DOI: 10.4017/gt.2009.08.04.003.00.

[77] U. Diaz-Orueta, D. Facal, H.H. Nap and M. Ranga. "What is the key for older people to show interest in playing digital learning games? Initial qualitative findings from the LEAGE project on a multicultural european sample". Games for Health Journal. Vol. 1, Issue 2, pp. 115-123. April, 2012. ISSN: 2161-783X (Print) 2161-7856 (Online). DOI: $10.1089 / \mathrm{g} 4 \mathrm{~h} .2011 .0024$.

[78] D. Grammenos, A. Savidis and C. Stephanidis. "Designing universally accessible games". Comput. Entertain. Vol. 7, Issue 1, pp. 8:18:29. February, 2009. ISSN: 1544-3574 (Online). DOI: 10.1145/1486508.1486516.

[79] American Occupational Therapy Association. "Occupational therapy practice framework: domain and process". American Journal of Occupational Therapy. 2nd Ed. Vol. 62, Issue 6, pp. 625-683. ISBN: 978-1-56900265-0. 2008.

[80] A. Fisher. "Overview of performance skills and client factors". In Pedretti's occupational therapy: Practice skills for physical dysfunction. Mosby/Elsevier Health Sciences. St. Louis, MO, USA. 6th Edition. Vol. 1, pp. 372-402. ISBN-13: 9780323031530. 2006.

[81] K.A. Ertel, M.M. Glymour and L.F. Berkman. "Effects of social integration on preserving memory function in a nationally representative US elderly population". Am J Public Health. Vol. 98, Issue 7, pp. 1215-1220. July, 2008. ISSN: 0090-0036 (Print) 1541-0048 (Online). DOI: 10.2105/AJPH.2007.113654.

[82] J.A. Garcia Marin, K. Felix Navarro and E. Lawrence. "Serious games to improve the physical health of the elderly: A categorization scheme". International Conference on Advances in Human-oriented and Personalized Mechanisms, Technologies, and Services. Barcelona, Spain. October 23-28, 2011.

[83] P. Rego, P.M. Moreira and L.P. Reis. "Serious games for rehabilitation a survey and a classification towards a taxonomy". 5th Iberian Conf. Information Systems and Technologies (CISTI). June 16-19, 2010.

[84] G. Alankus, A. Lazar, M. May and C. Kelleher. "Towards customizable games for stroke rehabilitation". 28th international conference on Human factors in computing systems (CHI '10). Atlanta, GA, USA. April 10-15, 2010.

[85] E. Flores, G. Tobon, E. Cavallaro, F.I. Cavallaro, J.C. Perry and T. Keller. "Improving patient motivation in game development for motor deficit rehabilitation". International Conference on Advances in Computer Entertainment Technology (ACE '08). Yokohama, Japan. December 3-5, 2008.

[86] L. Gamberini, F. Martino, B. Seraglia, A. Spagnolli, M. Fabregat, F. Ibanez, M. Alcaniz and J.M. Andrés. "Eldergames project: an innovative mixed reality table-top solution to preserve cognitive functions in elderly people". 2nd conference on Human System Interactions (HSI'09). Catania, Italy. May 21-23, 2009. 
[87] C. Basak, W.R. Boot, M.W. Voss and A.F. Kramer. "Can training in a real-time strategy video game attenuate cognitive decline in older adults?". Psychology and Aging. Vol. 23, Issue 4, pp. 765-777. December, 2008. ISSN: 0882-7974 (Print) 1939-1498 (Online). DOI: 10.1037/a0013494.

[88] L.A. Whitlock, A. Collins-Mclaughlin, J.C. Allaire. "Training requirements of a video game-based cognitive intervention for older adults: Lessons learned". Human Factors. Vol. 54, Issue 27, pp. 2343-2346. September 2010. ISSN: 1541-9312. DOI: 10.1177/154193121005402726.

[89] A. Grimes, V. Kantroo and R.E. Grinter. "Let's play!: mobile health games for adults". 12th ACM international conference on Ubiquitous computing (Ubicomp '10). Copenhagen, Denmark. September 26-29. 2010.

[90] W. White, B. Sowell, J. Gehrke and A. Demers. "Declarative processing for computer games". ACM SIGGRAPH symposium on
Video games (Sandbox '08). Los Angeles, CA, USA. August 9-10, 2008.

[91] E. Zwartkruis-Pelgrim and B. Ruyter. "Developing an adaptive memory game for seniors". 2nd International Conference on Fun and Games. Eindhoven, The Netherlands. October 20-21, 2008.

[92] S.L. Chu Yew Yee, H. Been-Lirn Duh, and F. Quek. "Investigating narrative in mobile games for seniors". 28th international conference on Human factors in computing systems (CHI '10). Atlanta, GA, USA. April 10-15, 2010.

[93] N. Holmes. "Digital technology, age, and gaming". Computer. Vol. 38, Issue 11, pp. 108-107. November, 2005. ISSN: 00189162. DOI: 10.1109/MC.2005.376.

[94] M. Chilcott and A. Smith. "Ageing well and learning through online immersive participation using a multi-user web $3 \mathrm{~d}$ environment". Conference in Games and Virtual Worlds for Serious Applications (VS-GAMES). Genoa, Italy. May 4-6, 2011. 